\title{
Mi experiencia como editor
}

\author{
Santiago Gallo-Reynoso \\ Departamento de Endoscopia Gastrointestinal, Instituto Nacional de Ciencias Médicas y Nutrición Salvador Zubirán, Mexico City, Mexico
}

En este número de la revista ha llegado una colaboración especial de un exeditor de la revista Endoscopia. Después de considerarlo mucho decidimos publicarla tal cual nos llegó. Creemos importante publicarla, ya que podemos decir que algunas cosas nunca cambian o lo hacen muy poco.

F.I. Téllez-Ávila

E. Murcio-Pérez

Mi experiencia como editor

La primera revista mexicana en la que trabajé como editor fue la Revista Mexicana de Gastroenterología, órgano oficial de la asociación del mismo nombre. En ella encontré y conocí durante mi especialización (1976 y 1977) los primeros nombres de los investigadores mexicanos y las patologías respectivas que se encuentran en nuestro país. Me llamó la atención saber que los doctores V. Arrubarena y G. de León fueran sus editores durante ocho años.

Inicié mi experiencia como editor en esa revista en 1988 porque los doctores M. Dehesa y L. Uscanga me invitaron inicialmente como editor asociado durante tres años, al término de los cuales tomé, junto con el Dr. H. Hurtado, el puesto de editor (1991-1993). Durante el primer año trabajamos conjuntamente, pero después tuve que trabajar solo porque él desempeñó puestos importantes en la Mesa Directiva de la Asociación, de la que fue vicepresidente y presidente, cargos que obviamente le impidieron realizar su trabajo editorial. Mis editores asociados, los doctores de la Garza y Marín no tuvieron tampoco mucha participación en el trabajo editorial. Me satisfizo poder hacer mejoras a la revista durante mi trabajo, como cambiarla de casa editorial, incluir fotografías a color, mejorar su calidad académica y también escribir un «rincón del editor» en el que analizaba los artículos o escribía pequeños ensayos sobre el quehacer médico; incluso llegue a pedirle a nuestra conocida y admirada escritora Ángeles Mastreta un manuscrito para publicarlo, fue una descripción atinada y humorística sobre una «amiga» a quien le practicamos un estudio endoscópico en el Instituto Nacional de Ciencias Médicas y Nutrición Salvador Zubirán.

La segunda revista en la que trabajé fue Endoscopia, órgano oficial de la Asociación Mexicana de Endoscopia Gastrointestinal, que inició su publicación a finales del año 1990. Sus editores fundadores fueron los doctores A. de la Torre y M. Marañón, sus editores durante los dos años siguientes. Ellos me invitaron en 1993 a que me uniera a su trabajo editorial y lo acepté con gusto, pero con la condición de empezar a realizarlo a partir de 1994, cuando terminara mi compromiso con la revista Gastroenterología. Por alguna causa

\section{Correspondencia:}

*Santiago Gallo-Reynoso

Departamento de Endoscopia Gastrointestinal

Instituto Nacional de Ciencias Médicas y

Nutrición Salvador Zubirán

Vasco de Quiroga, 15

Col. Belisario Domínguez

Sección XVI, Del. Tlalpan

Fecha de recepción: 01-02-2019

Fecha de aceptación: 07-02-2018

DOI: 10.24875/END.M19000008
Disponible en internet: 06-05-2019 Endoscopia. 2019;31:55-57 www.endoscopia-ameg.com

E-mail: santiagallo@ hotmail.com

0188-9893/@ 2019. Asociación Mexicana de Endoscopia Gastrointestinal, publicado por Permanyer México SA de CV, todos los derechos reservados. 
desconocida para mí, el Dr. de la Torre renunció a seguir siendo editor de la revista y tomé su lugar como editor en 1993, pero igualmente el Dr. Marañón dejó en mis manos el trabajo en pleno y me encontré con el hecho de ser editor «único» de ambas revistas al mismo tiempo durante ese año.

Tres años después, en 1996, el Dr. F. Ochoa animosamente me pidió que lo aceptara en el trabajo editorial y lo acepté con gusto, sin embargo solamente asistió a las reuniones para integrar dos números de la revista; no lo volví a ver y a partir del año siguiente retiré su nombre como editor. Invité en 1999 a la Dra. A. Hernández a ser editora asociada, lo que gustosamente aceptó, pero después de un inicio entusiasta también desistió sin decir ninguna palabra.

En ese año decidí, sin preámbulo alguno y para llamar la atención de los miembros de la Asociación sobre la revista, cambiar la forma del contenido y la portada, quité su logotipo original e introduje fotografías endoscópicas a color en ella, y de fondo le puse un feo color verde pistacho. El resultado fue que no les gustó la portada ni que le quitara su logotipo, pero no hubo ningún comentario sobre la forma del contenido, que también había cambiado. Volví a darle colores serios, le coloqué de nuevo el logotipo en un recuadro pequeño y se quedaron las fotografías, con lo que ya nadie opinó nada.

En el año 2000 invité a ocho médicos endoscopistas a formar un Comité Editorial que vigilara el contenido, revisara los trabajos y motivara a los miembros de la Asociación a mandar sus escritos a nuestra revista, pero teníamos como rival a la de Gastroenterología, que tenía mejor rating y los artículos publicados en ella tenían más valor y eran reconocidos internacionalmente. Les expliqué mis proyectos y salí emocionado con la respuesta, ya que todos se mostraron dispuestos y motivados, pero después me cansé de pedirles su participación y volví a trabajar solo, dedicado al trabajo editorial y no al de animador fracasado.

Traté infructuosamente de que fuera incluida en el Index Medicus, publicación mensual norteamericana que mostraba el contenido de los índices de las más prestigiadas revistas del mundo (recuérdese que no había internet y todo era impreso), pero conseguí introducirla en el Índex Latinoamericano, y así los autores nos dimos a conocer en todo el continente americano, mejorando el rating de la revista.

Mi trabajo editorial consistía en recibir los trabajos que se recibían para su publicación, revisarlos tanto en su estilo literario como en su calidad académica y forma de tratar las estadísticas, ver que tuvieran su resumen en español e inglés (me pasaba mucho tiempo en rehacer el escrito o incluso traducir al inglés el champurrado que mandaban); revisaba que las notas estuvieran ordenadas y correspondieran con el texto y también me aseguraba de que los pies de las fotografías fueran adecuados e igualmente los «reacomodaba» si era necesario. Pocas veces los autores se quejaron de mi ayuda (recuerdo que en tantos años solamente dos autores airadamente me dijeron que les había cambiado el sentido de lo que querían expresar, pero con ambos llegué a buenos acuerdos y no retiraron sus artículos).

Establecía el orden de los artículos por su calidad y trascendencia y una vez entregado el trabajo a la imprenta volvía a revisarlo para que estuviera perfectamente armado, y la posición y tamaño de las imágenes en el texto fueran los adecuados, para que concordaran en las páginas, y después iba a la imprenta para ver que los negativos de las fotografías estuvieran adecuadamente orientados y no hubieran intercambiado los pies de las fotos. Recuerdo que esto último lo hacía cuando iba de un hospital al otro al mediodía, siempre estaba urgido de hacerlo porque la imprenta no iniciaba su tiraje hasta que yo diera el "visto bueno» (la orden de hacerlo) y no debía haber demoras para salir a tiempo.

De forma desagradable me enteré de que dejaría el trabajo editorial. Había ido a la reunión nacional realizada en Mazatlán a finales del 2000 para presentar mi informe anual y regresé antes del discurso del presidente entrante porque tuve que salir para no perder el avión. La siguiente semana, ya en México, la Dra. C. Piña (quien era entonces mi principal ayudante de trabajo) me preguntó "¿qué le pareció el descanso al que lo mandaron?". Al principio no entendí la pregunta y al pedir que me lo explicara me dijo que el nuevo editor era el Dr. A. Güitrón, ya que el Dr. E. Gallardo al hacer su discurso de toma de posesión de la presidencia, posiblemente pensando que estaba yo presente en el auditorio, me agradeció ampliamente el haber sido editor de la revista y concluyó diciendo «es tiempo de darle un descanso". Experimenté un sentimiento desagradable, puesto que esa mañana, en Mazatlán, había desayunado con ellos dos y no me comunicaron directamente sus planes.

Sin embargo, no terminó aquí mi trabajo editorial, porque en el 2003 el Dr. Güitrón renunció intempestivamente. El Dr. A. Corral, quien tomó ese año la presidencia de la Asociación, me pidió que regresara en forma de emergente para sacar el último número del año y continúe por petición de la Dra. L. Grau (presidente del 
año 2005), ejerciéndolo por otro año. Terminé así mis labores editoriales con el último número del año y dejé finalmente el trabajo editorial en manos de un comité encabezado por el Dr. S. Sobrino.

Puedo decir con orgullo que durante mi trabajo como editor la revista no fue nunca una carga económica para la Asociación, ya que yo mismo vendía la mayoría de los anuncios que salían en ella y así la financiaba. Recuerdo haber acuñado dos frases que intercalaba en mis noticias y escritos: "Las asociaciones tienen las publicaciones que se merecen» y «Esta revista es tuya... ¡Utilízala!".

No quiero dejar de mencionar a un personaje entrañable durante estos años de trabajo, el Sr. H. Laguna, quien fue durante todos los años de ambas revistas $\mathrm{mi}$ contacto con las casas editoriales. "Mere» realizaba un trabajo incansable, no solo por llevar y traerme galeradas, acompañarme a vender publicidad, recordarme y "obligarme» a ir a ver los pies de figura y entregar en tiempo la revista, sino por ser un colaborador y amigo en el trabajo. También reconozco el apoyo del Sr. L. Bravo, director de la compañía Fuerza Editorial, con quien empecé mi trabajo, me ayudó a ver mi responsabilidad y me enseñó muchas cosas que recuerdo con mucho afecto.

\section{Corolario}

El trabajo editorial es como cualquier otro, si se toma seriamente puede uno hacerlo y desarrollarse, crece uno al estar activo, se siente uno útil, y si además se le encuentra gusto y se goza, se respeta uno y cumple una responsabilidad social. Finalmente, como cualquier trabajo humano bien realizado, te dignifica al hacerlo y te permite trascender. 